\title{
Lean LaunchPad and Customer Discovery as a Form of Qualitative Research
}

\section{Dr. Cory Hixson, Rowan University}

Cory is an Assistant Professor of Experiential Engineering Education (ExEEd) at Rowan University. He earned his B.S. in Engineering Science (2007), M.S. in Industrial and System Engineering (2014) and $\mathrm{Ph} . \mathrm{D}$. in Engineering Education (2016). Cory has experience as both a professional engineer and high school educator. His professional interests are understanding the interaction between engineering education pedagogy and entrepreneurship, faculty technology commercialization experiences, and institutional policies that influence both engineering education and entrepreneurship. In July 2018, Cory will begin a new faculty position at Colorado Christian University.

\section{Dr. Ella Lee Ingram, Rose-Hulman Institute of Technology}

Ella L. Ingram is an Associate Professor of Biology and Director of the Center for the Practice and Scholarship of Education at Rose-Hulman Institute of Technology. Her educational research interests include promoting successful change practice of STEM faculty, effective evolution and ecology instruction, and facilitating undergraduate research experiences. Her teaching portfolio includes courses on: nutrition, introductory biology, ecology and environmental studies, evolution, evolutionary medicine, and research practices in science.

\section{Dr. Rachel McCord, University of Tennessee, Knoxville}

Rachel McCord is a a Lecturer and Research Assistant Professor in the Engineering Fundamentals Division at the University of Tennessee in Knoxville. She received her Ph.D. in Engineering Education from Virginia Tech. Her research interests include the impact of metacognitive and self-regulated learning development on engineering student success, particularly in the first year as well as practices to encourage the connection between the research-practice cycle.

\section{Dr. Julia M. Williams, Rose-Hulman Institute of Technology}

Dr. Julia M. Williams is Interim Dean of Cross-Cutting Programs and Emerging Opportunities and Professor of English at Rose-Hulman Institute of Technology. Her research areas include technical communication, assessment, accreditation, and the development of change management strategies for faculty and staff. Her articles have appeared in the Journal of Engineering Education, International Journal of Engineering Education, IEEE Transactions on Professional Communication, and Technical Communication Quarterly, among others. 


\section{Lean LaunchPad ${ }^{\circledR}$ and Customer Discovery as a Form of Qualitative Research}

In this theoretical paper, we highlight the scholarship of integration by exploring how customer discovery connects to other methodologies in engineering education research and the opportunities for using this methodology in engineering education research. As a result of the National Science Foundation's Innovation Corps (I-Corps) and I-Corps for Learning initiatives, the Lean LaunchPad $\AA /$ Customer Discovery methodology has grown in popularity within academic institutions, particularly in business and entrepreneurship education. In addition, the Lean LaunchPad $\AA /$ Customer Discovery approach has helped startups, individuals, academics, and students test the potential of an idea, make important decisions about the structure, value, and implementation of their projects, and develop a minimum viable product, service, or offering. While the Lean LaunchPad $\AA / C$ Customer Discovery approach is relatively new to the fields of business, engineering education, and entrepreneurship education, its methodological background emerges from well-established qualitative research techniques.

We first describe the Lean LaunchPad®/Customer Discovery process and give examples of its current use in academia. Next, we explain the connections between the Lean LaunchPad $\mathbb{R} /$ Customer Discovery approach and specific forms of qualitative research like design-based research, action research, and qualitative interviewing. Finally, we offer a detailed example of how our team used the Lean LaunchPad ${ }^{\circledR} /$ Customer Discovery approach to conduct an engineering education action research project. This example serves to clarify how the Lean LaunchPad $\AA /$ Customer Discovery approach can be successfully applied, validated by funding received after our use of the process to develop a program. We expect that this theoretical work will add value to individuals interested in conducting action-oriented educational research projects for two reasons. First, we show how robust qualitative research methodologies provide the foundation for a popular market research approach. Second, we give an example of using this approach in an educational context. Our motivation is to expand the breadth of methodologies available to researchers and practitioners.

\section{Introduction}

Our aim in this theoretical paper is to make connections between the integrated Lean LaunchPad $\AA / C u s t o m e r$ Discovery processes and more known forms of qualitative research such as design-based research, action research, and qualitative interviewing. We seek to explore this connection for multiple reasons. First, we find that both the lean and customer-centric characteristics of this approach are synonymous with engineering education's iterative, adaptive, and user-centered forms of qualitative research. Second, we, like the National Science Foundation, predict these processes will have a positive impact on educational technologies, programs, courses (Chavela Guerra et al. 2014), and engineering education research. Lastly, while we are not the developers of Lean LaunchPad®/Customer Discovery process and have no financial stake in promoting it, our team is successfully using this approach and believe the insights from this work are valuable to our peers in engineering education. Given these goals, we recognize that some terms we use are new to the engineering education community; therefore, Table 1 serves to introduce common vocabulary. 
Table 1. Key definitions of terms associated with Lean LaunchPad® and Customer Discovery.

\begin{tabular}{|l|l|}
\hline Term & Definition \\
\hline Customer & An individual or group who will buy or use the product or service \\
\hline Stakeholder & $\begin{array}{l}\text { An individual or group who has a vested interest in the product or } \\
\text { service (e.g., customer, manufacturer, regulator, gatekeeper, etc.) }\end{array}$ \\
\hline Opportunity Space & $\begin{array}{l}\text { The area of interest for the entrepreneur, program developer, researcher, } \\
\text { etc. (e.g., green housing, student programming, professional skills } \\
\text { development) }\end{array}$ \\
\hline Lean (agile) & $\begin{array}{l}\text { An approach that seeks to decrease certain negative process } \\
\text { characteristics (e.g., waste, time, unnecessary redundancy) while } \\
\text { maximizing positive process characteristics (e.g., productivity, quality, } \\
\text { and cost). "Lean" is often used as an adjective to another term (e.g., lean } \\
\text { manufacturing, lean product development, lean software development) }\end{array}$ \\
\hline Hypothesis & A belief or assumption that should be tested. \\
\hline
\end{tabular}

The Lean LaunchPad® and Customer Discovery methodologies are two distinct, but often integrated, entrepreneurship education and business startup approaches. The integrated Lean LaunchPad®/Customer Discovery methodology has been adopted by many entrepreneuriallyfocused courses within our universities and by entrepreneurial organizations around the globe. The Lean LaunchPad $\AA$ process was developed by Steve Blank while he was teaching at Stanford University, to support students as they explored entrepreneurial business models for new and innovative products and services. It results from scholars combining Blank's experience as a serial entrepreneur (Blank 2013; Anderson 2017), Eric Ries's "lean" thinking (Ries 2011), and Alexander Osterwalder's work on generating business models (e.g., Osterwalder \& Pigneur 2010; Osterwalder et al. 2014). VentureWell, an entrepreneurially-oriented non-profit organization well-known within the ASEE community that hosts Lean LaunchPad® Instructor courses, describes the approach the following way:

It emphasizes experiential learning, a flipped classroom and immediate feedback as a way to engage students with real world entrepreneurship. Students learn by proposing and immediately testing hypotheses. They get out of the classroom and talk to customers, partners and competitors and encounter the chaos and uncertainty of commercializing innovations and creating new ventures...students will do, rather than plan to do. Unlike many approaches to entrepreneurship education, Lean LaunchPad® does not rely on static case studies or fixed models; it challenges students to create their own business models based on information derived from personal engagement rather than secondhand market research. (From https://venturewell.org/lean-launchpad/ emphasis ours) 
While VentureWell's text centers on entrepreneurship, we have emphasized the aspects of the approach that will become essential to our discussion later in this work.

The Customer Discovery process is a methodology that typically occurs in harmony alongside Lean LaunchPad $\AA$. While Lean LaunchPad ${ }^{\circledR}$ represents an overarching methodology, the customer discovery process is often enacted as a sub-process in which the practitioners (those attempting to launch a product or start a company) use the knowledge gained through iterative hypothesis testing to define customer archetypes, understand these archetypes' most important experiences, and show how a new product or service may add value to each archetype.

The integrated Lean LaunchPad $\mathbb{R} /$ Customer Discovery process begins by clarifying an opportunity space, identifying customers and stakeholders, and generating hypotheses about both the product or process and customers or stakeholders within this space. Next, and before any actual development occurs, practitioners collect data relevant to these hypotheses. Data collection could involve interviewing customers or stakeholders, observing customers or stakeholders in meaningful environments, surveying for satisfaction or decision-making criteria, acquiring analytics data, testing low-fidelity prototypes, or collecting other forms of data. These varied methods all contribute to understanding the experiences of relevant stakeholders, validating existing hypotheses, refining product or process ideas, and creating new hypotheses to test. This iterative and focused hypothesis testing represents the "lean" aspect of the process, because the practitioners only pursue the outcomes of hypotheses that are likely to contribute to eventual success. Therefore, they avoid the wasted resources that would result from pursing all ideas. At the same time, customer archetypes are continuously developed and refined from the data, leading to a robust alignment between the final products, services, or offerings developed; the key stakeholders; and the business model that offers the highest likelihood of success.

As we've described in the previous paragraphs, the Lean LaunchPad®/Customer Discovery process emerges from and is most used in the business world. But, examples from higher education also show the value of the approach. In 2011, the NSF established the I-Corps (Innovation Corps) program to promote the transfer of NSF-funded discoveries into products and services valued by the open (or non-academic) market. The program requires faculty, graduate students, and industry mentors to test their hypotheses (often involving hundreds of interviews, strategic focus groups, and feedback from technical and business experts) in order to determine the impact and potential business model of an academic discovery. The success of the I-Corps program led the NSF and ASEE to partner to offer the I-Corps for Learning (I-Corps L) program. This program is like the traditional I-Corps program but applied to educational products, services, or offerings derived from education research and assessment (Chavela Guerra \& Smith 2016; Chavela Guerra et al. 2014). A more thorough explanation of this program and examples of I-Corps L projects are available at: https://www.asee.org/i-corps-1/about and http://personal.cege.umn.edu/ $\sim$ smith/docs/ASEE_Scaling_Innovations_Panel-I-Corps-L.pdf. In addition to these programs, the Lean LaunchPad $\AA /$ Customer Discovery process has also been adopted at the grassroots faculty level by many educators to teach product development, venture development, and "voice of the customer" courses.

In sum, the Lean LaunchPad®/Customer Discovery approach has been widely adopted in certain sectors of academia. From an anecdotal perspective, it has shown its effectiveness as 
practitioners decide the suitable next steps in any project. As engineering education researchers,

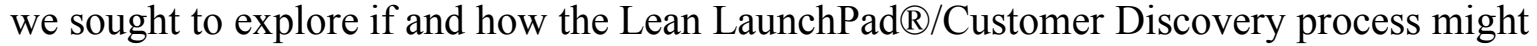
improve our scholarly work and discovered that this process both resembles and uses traditional forms of social science research. We seek to highlight this connection throughout the rest of this paper.

\section{Lean LaunchPad®/Customer Discovery as a Qualitative Methodology}

Case and Light (2011) called for more contributions to the qualitative methodology tool box to give researchers the opportunity to broaden the research questions that the engineering education community investigates. In our opinion, the Lean LaunchPad $® / C u s t o m e r$ Discovery process fits this call because it emphasizes and preferences direct input from stakeholders in a particular area to not only define and shape the current research questions, but also to direct future research decisions and to enact broader impacts. In addition, the approach uses many of the "lean" premises called for in the current practices of engineering education: fast and informative failure, iteration, and implementation (Crawley, Malmqvist, Ostlund, \& Brodeur, 2007). At their core, qualitative researchers explore the experience of research subjects using a holistic approach that recognizes "the complexity of human behavior" (Koro-Ljungberg \& Douglas 2008). Further, qualitative research describes people, events, and patterns, but often goes beyond description to explore how and why the world appears and behaves as it does. The Lean

LaunchPad $\AA /$ Customer Discovery process accomplishes these same goals through customer discovery and so fits with both the purpose and intent of qualitative research. In particular, customer discovery links validated sets of hypotheses to archetypes that combine patterns of human cognition and behavior.

In their guest editorial for the Journal of Engineering Education, Baillie \& Douglas (2014) reminded engineering education researchers of the key parameters of qualitative research (calling on Crotty's 1998 analysis): epistemology (the researcher's stance regarding knowledge), theoretical framing (lens of analysis), methodology ("philosophical justification for the research design"), and methods (the "particular procedures" accomplished by the researcher). If the Lean LaunchPad $\mathbb{R} /$ Customer Discovery process is a qualitative methodology, it must have elements that fit these parameters. We contend that it does.

We place the Lean LaunchPad ${ }^{\circledR} /$ Customer Discovery process in the epistemic pragmatism epistemology. Scholars using the customer discovery approach often believe they have a realworld opportunity (or problem to solve) and are open to exploring the breadths and depths of the opportunity space and the archetypes the space contains. In this sense, an adopted solution must fit the criteria established by the constraints of the system. Impractical solutions are not entertained other than to remove them from consideration. Continual reflection (e.g., "Am I closer to solving the problem?") guides all the remaining considerations. Pragmatism is forwardlooking (what can and should be done) rather than focused on exploring the past. In this way, the pragmatic approach is direct and actionable; practitioners seek a direction and justification to the next steps one should take.

The theoretical frameworks most suited to the Lean LaunchPad®/Customer Discovery process are action research and design-based research (DBR). The practitioners and scholars engaging in 
customer discovery, action research, or DBR are vested in the answers received, and often the same individuals are both doing the research and doing the doing. These three frameworks are similar in that they address a specific problem, can use a variety of research methods, and are iterative such that as the work shows new possibilities, the direction of the work may change. However, the goals and agency of the scholars and practitioners determine whether the Lean LaunchPad $\mathbb{R} /$ Customer Discovery process more resembles action research or DBR (Wang \& Hannafin 2005). Often the goal of the Lean LaunchPad®/Customer Discovery process is not to generate theory, but to design a product or service that provides value. This goal aligns with the goal of action research whereas a goal for theory development would align with DBR (Peer Group 2006). In addition, when researchers begin the project as both researchers and designers, the project is likely related to DBR (as opposed to an action research project in which the researchers' role is often a step removed from the designers' role) (Wang \& Hannafin 2005; Peer Group 2006).

To further explore the relationship between the Lean LaunchPad®/Customer Discovery process and action research, consider that in enacting action research, new information can cause a stop in the project or a significant direction change of the action research project. This specific feature of action research is a core difference between action research as a theoretical disposition and other theoretical framings. By definition, the research and implementation parts of the project can change direction during the process. The Lean LaunchPad $\AA / C$ Customer Discovery process fits these models; scholars using this process never stop doing customer discovery. The hypotheses change (for example, a change in focus and narrowing of decisions) as they are validated, answered, or justified, moving one to the next step (a process consistent with the epistemic disposition of pragmatism). As enacted through Lean LaunchPad $\AA /$ Customer Discovery, the research and development process is not exhaustive, rather scholars do meaningful sampling to inform developmental decision-making. This sampling emerges from analyzing one's hypotheses in concert with various possible customer archetypes. As mentioned previously, the Lean LaunchPad $\AA /$ Customer Discovery process is enacted by those who want to seize an opportunity or solve a problem in practice (e.g., discover what customers or users want); therefore, the findings likely lead to a combination of new implementations, new hypotheses, and new action research or DBR studies.

The methods befitting the Lean LaunchPad®/Customer Discovery process include interviews, reflective essays, documentary analysis, behavioral observations, and focus groups. Most commonly (at least in the business world), customer discovery uses interviews with stakeholders, employing carefully designed, open-ended prompts that yield rich detail about customer needs and opportunities for the practitioner. For products or services, observation can yield information about experienced need or perceived value. For example, if participants in a program check email or take frequent unscheduled breaks, they are telling service providers that the program is not compelling or is not meeting their needs. As scholars, we often use literature reviews, conversations with other researchers, and observations of students to seed our scholarly project ideas. These methods are consistent with the information gathering necessary to perform the Lean LaunchPad®/Customer Discovery process.

As with other qualitative methodologies (e.g., case studies), the Lean LaunchPad $® / C$ ustomer Discovery process might be critiqued regarding generalizability or transferability. For instance, 
since interaction with stakeholders is required, this methodology might suffer from missing stakeholders or failing to reach a broad enough range of stakeholders. Scholars should pursue diverse stakeholders through careful attention to the system in which the discovery is occurring. The issues of generalizability and transferability are problematic for action research or DBR approaches as the scholars enacting these approaches are vested in a specific project. However, the Lean LaunchPad $\mathbb{\circledR} /$ Customer Discovery process operates from a needs-assessment perspective (e.g., "What are your experiences related to [opportunity space]?") rather than a confirmatory approach ("Do you think our program is the right solution?"). In this way, the Lean LaunchPad $\AA /$ Customer Discovery process is like Borrego's recommendation for rigorous research to use "research questions of broad, rather than localized, appeal" (2007). Further, we posit that the Lean LaunchPad ${ }^{\circledR} /$ Customer Discovery process is like grounded theory in that researchers withhold making decisions at the beginning of the work, and they finish discovery or data collection when "theoretical saturation" occurs. In addition, Yin's (2014) description of analytical generalization for the case study methodology applies to the Lean LaunchPad $\AA /$ Customer Discovery process, particularly that of literal replication and theoretical replication. For literal replication, researchers design cases to be similar enough to corroborate one another (assuming these conditions exist within the cases). For theoretical replication, researchers design cases to satisfy different theoretical conditions that can be analyzed. Through the Lean LaunchPad $\mathbb{\circledR} /$ Customer Discovery process, educational researchers/program developers can satisfy literal replication by sampling different individuals within the same stakeholder archetype (e.g., undergraduate program directors) and theoretical replication by sampling stakeholders in different archetypes (e.g., undergraduate program directors and NSF program officers). Like other qualitative research methodologies, the Lean LaunchPad ${ }^{\circledR} /$ Customer Discovery process is generalizable for its intended purpose: to better understand aspects of human behavior and inform iterative decision-making.

Given the connections just made, we recognize that action research and DBR as theoretical frameworks can be enacted via other methodologies, and that other methods may also be suited to the Lean LaunchPad®/Customer Discovery process. Our goal is not to give a tutorial, but instead to highlight connections between the Lean LaunchPad $\mathbb{R} /$ Customer Discovery process and traditional forms of qualitative research. With our particular work (described in the next section), we chose the Lean LaunchPad®/Customer Discovery process for several reasons. First, we recognized that our project involved more diverse stakeholder groups than past projects, increasing our need for understanding how the various stakeholders might gain from our exploration of the opportunity space. In addition, we wanted to move forward with other parts of our project, consistent with an action research or DBR approach, but didn't want to go down a path that our stakeholders did not value. Second, we took to heart the perspective "Does anyone care about our fledgling educational innovation?" and sought to answer this question. Finally, the lead author has extensive experience both enacting the Lean LaunchPad $\mathbb{R} /$ Customer Discovery process and teaching it in technical entrepreneurship courses. When he approached the remaining authors about using the Lean LaunchPad®/Customer Discovery process to explore this space, they welcomed the opportunity to expand their qualitative research literacy and toolbox. The connections between Lean LaunchPad $\mathbb{B} /$ Customer Discovery process and other research methods appeared while conducting our exploration. These various reasons combined to make the Lean LaunchPad $\mathbb{R} /$ Customer Discovery process attractive over other options, despite the need to conduct many interviews across at least six stakeholder groups. 


\section{Using the Lean LaunchPad $® /$ Customer Discovery process in Engineering Education Research}

We adopted the Lean LaunchPad $\AA /$ Customer Discovery process to conduct an engineering education action research project, with success defined as accomplishing discovery, enacting development, securing funding, and initiating implementation. Several years ago, educators at Rose-Hulman Institute of Technology lamented that despite best efforts in faculty development and institutional communication, engineering education research often didn't penetrate their context. Low adoption of research-based instructional strategies prevailed, so they sought to explore ways to incorporate more engineering education research into their environment. In exploring solutions with external colleagues, one idea emerged: place advanced engineering education graduate students in institutions seeking greater adoption of engineering education research. This idea solved two problems, the lack of subject-matter expertise (engineering education research) in traditional engineering departments and the need for engineering education graduate students to gain experience with faculty life before entering their first faculty appointment. We identified multiple models for this placement experience, then field-tested one model by creating a collaboration with one host institution and one graduate program. This collaboration proved successful (Hixson Ingram Williams Matusovich \& McCord 2015; McCord Hixson Ingram \& McNair 2014), with four students experiencing placement, impacting two offices and many faculty members at the host institution.

When presenting the project to colleagues at conferences and in other venues, we perceived significant interest from other potential host institutions. We wondered whether our existing model would scale and how best to scale this experience. To test whether the larger engineering education community would value our prototype, we began our Lean LaunchPad®/Customer Discovery process. We hypothesized that "A placement experience in which advanced engineering education graduate students serve as engineering education subject-matter experts for traditional engineering departments, while gaining experience as a faculty member, would be valued, is achievable, and is economical". (We had other hypotheses but those are beyond the scope of this paper.)

Next, we identified key stakeholder archetypes (graduate students, host institutions/departments, graduate program directors and advisors, funding agencies, etc.), and specific individuals who fit into these groups. For example, one major stakeholder group was funding agencies. The RoseHulman Institute of Technology corporate and foundations relations director connected us to two foundation officers interested in graduate training experiences. Another stakeholder group was teaching-focused institutions (for example, engineering departments without formal resident “engineering education" expertise).

After exploring methods to get stakeholder information, we chose interviews as the method of choice, primarily because we felt this approach would give us the data needed to confirm (or refute) our hypotheses. Further, this method was both cost-effective and familiar to most of our stakeholder. We developed a series of open-ended questions specific to each stakeholder group that explored various issues relevant to our opportunity space. For example, we included questions related to existing and desired professional development opportunities for graduate 
students, institutional context for visiting scholars, missed opportunities for engineering education research, integration of research-based instructional practices, outcomes of interest to project funders, and more. In developing these questions, we created questions that centered on problems experienced by the stakeholders and the opportunities they would like to have, rather than questions about our specific prototype. For example, we asked graduate students "What professional development experiences do you believe you should have before you graduate?" as opposed to - "Would you take part in a program where students engage in the following professional development experiences...?"

We secured IRB approval for this study and interviewed various stakeholders. So far, we have performed 25 interviews across six stakeholder groups and our recruitment for interviews continues. The data gathered through these interviews provided critical insights regarding our assumptions and contributed to the development of an expanded consortium model for the placement experience previously described. The interviews also helped our team secure the funding needed to carry out a two-year proof-of-concept. In summary, our team started with a problem, used the Lean LaunchPad $\AA /$ Customer Discovery process to learn from our stakeholders and explore our hypotheses, and have refined both our proposed solution and our customer discovery process in order to continuously gain insights within this opportunity space.

\section{Conclusion}

As mentioned previously, opportunities exist for expanded forms of qualitative research in engineering education (Case \& Light 2011). These expanded forms should follow what Baillie and Douglas (2014) describe as key parameters in qualitative research: epistemology, theoretical framing, methodology, and methods. Further, less than a decade ago Case and Light (2011) described seven emerging methodologies in engineering education research (e.g., case study, phenomenography, and more) and stated that “...a further deep engagement with issues of methodology is likely to yield a dramatic growth in the range of research findings that can be generated in the field" (pg. 207). Our analysis and experience with the approach indicates that the Lean LaunchPad $\AA / C$ ustomer Discovery process is a form of qualitative research that not only exhibits these key qualitative research parameters, but also offers actionable research insights that could lessen the divide between research and practice. The Lean LaunchPad®/Customer Discovery process has ties to both action research and design-based research while also presenting a unique stance among qualitative research methodologies. Rather than attempting to explain a phenomenon or clarify an experience (we acknowledge a simplification of other methodologies), the process seeks to develop/test relevant hypotheses, understand stakeholder groups, and identify "What opportunities exist?" The process takes on a more forward-looking perspective while remaining grounded in complex human behaviors and decision-making processes. The Lean LaunchPad $\mathbb{R} /$ Customer Discovery process formalizes an approach to consider a problem and opportunity space, understand stakeholders' perspectives, explore the range of solutions, and then develop and refine an intervention that satisfies stakeholders' expressed needs.

For researchers who are interested in this form of qualitative research, we recommend asking the questions:

- Who are the major stakeholders in the opportunity space (or integral to the problem)? 
- Who are the minor stakeholders (peripheral to the problem yet still involved)?

- What is the core opportunity/problem being experienced by stakeholders?

- What unmet need exists?

- What information is potentially available to each stakeholder group?

- What open-ended questions will support validating (or refuting) our hypotheses while also encouraging stakeholders to offer insights into stakeholder experiences and the nuances of the opportunity/problem?

Finally, we encourage more researchers to consider the Lean LaunchPad $\mathbb{\circledR} /$ Customer Discovery process as a tool within their research toolbox. This recommendation is especially valid for action-oriented questions and opportunity spaces that seek to close the research-to-practice gap. 


\section{References}

Anderson, M. K. (2017). Meghan Keaney Anderson/The Growth Show: Taking the lean startup from Silicon Valley to the State Department (interview with Steve Blank). Retrieved from https://soundcloud.com/the-growth-show/taking-the-lean-startup-from.

Baillie, C., and E. P. Douglas. (2014). Confusions and conventions: Qualitative research in engineering education. Journal of Engineering Education, 103, 1-7.

Blair, E. E., R. B. Miller, M. Ong, and Y. V. Zastavker. (2017). Undergraduate STEM instructors' teacher identities and discourses on student gender expression and equity. Journal of Engineering Education, $106,14-43$.

Blank, S. (2013). Why the lean start-up changes everything. Harvard Business Review, 91, 63-72.

Borrego, M. (2007). Conceptual difficulties experienced by trained engineers learning educational research methods. Journal of Engineering Education, 96, 91-102.

Case, J. M., and G. Light. (2011). Emerging research methodologies in engineering education research. Journal of Engineering Education, 100, 186-210.

Chavela Guerra, R. C., K. A. Smith, A. F. McKenna, C. Swan, R. Korte, S. Jordan, M. Lande, and R. MacNeal. (2014). Innovation corps for learning: Evidence-based entrepreneurship ${ }^{\mathrm{TM}}$ to improve (STEM) education. Frontiers in Education Conference, Madrid, Spain.

Chavela Guerra, R. C. and K. A. Smith. (2016). I-Corps ${ }^{\text {TM }}$ for Learning: Sustaining and scaling STEM education innovations for impact. Frontiers in Education Conference, Erie, PA.

Crawley, E., J. Malmqvist, S. Ostlund, D. R. Brodeur, and K. Edström. (2014). Rethinking engineering education: The CDIO approach (2nd ed.), Cham, Germany: Springer International Publishing.

Crotty, M. (1998). The foundations of social research: Meaning and perspective in the research process. London, UK: Sage Publications, Inc.

Hixson, C., E. L. Ingram, J. M. Williams, H. M. Matusovich, \& R. E. McCord. (2015). The rising engineering education faculty experience (REEFE). American Society of Engineering Education, Seattle, WA.

Huff, J. L. and H. R. Clements. (2017). The hidden person within the frustrated student: An interpretative phenomenological analysis of a student's experience in a programming course. American Society for Engineering Education Annual Conference \& Exposition, Columbus, $\mathrm{OH}$.

Koro-Ljungberg, M. and E. P. Douglas. (2008). State of qualitative research in engineering education: Meta-analysis of JEE articles, 2005-2006. Journal of Engineering Education, 97, 163-175.

McCord, R. E., C. Hixson, E. L. Ingram, \& L. D. McNair. (2014). Graduate student and faculty member: An exploration of career and personal decisions. American Society of Engineering Education, Indianapolis, IN.

Osterwalder, A. and Y. Pigneur. (2010). Business model generation: A handbook for visionaries, game changers, and challengers. Hoboken, NJ: John Wiley and Sons

Osterwalder, A., Y. Pigneur, G. Bernarda, A. Smith, and T. Papadakos. (2014). Value proposition design: How to create products and services customers want. Hoboken, NJ: John Wiley and Sons.

Peer Group, "What is Design-based Research?" A PEER Tutorial for Design-based Research, Instructional Technology Ph.D. Students - The University of Georgia, November 2006. [website]. Available: http://dbr.coe.uga.edu/explain01.htm. [March 14, 2018].

Ries, E. (2011). The lean startup: How today's entrepreneurs use continuous innovation to create radically successful businesses. New York, NY: Crown Publishing.

Wang, F., \& Hannafin, M. J. (2005). Design-based research and technology-enhanced learning environments. Educational Technology Research and Development, 53(4), 5-23.

Yin, R. K. (2014). Case study research: Design and methods (5th ed.). Thousand Oaks, CA: Sage Publications, Inc. 